\title{
Glycoproteomic analysis of plasma from patients with atopic dermatitis: CD5L and ApoE as potential biomarkers
}

\author{
Won Kon Kim ${ }^{1 *}$, Hyang-Ran Hwang ${ }^{1 *}$, \\ Do Hyung Kim ${ }^{1}$, Phil Young Lee", \\ Yu Jung $\ln ^{1}$, Hye-Young Ryu ${ }^{2}$, \\ Sung Goo Park ${ }^{1}$, Kwang-Hee Bae ${ }^{1,3}$ \\ and Sang Chul Lee ${ }^{1,3}$ \\ ${ }^{1}$ Translational Research Center, KRIBB \\ Daejeon 305-806, Korea \\ ${ }^{2}$ Department of Pediatrics \\ SUN General Hospital \\ Daejeon 301-070, Korea \\ ${ }^{3}$ Corresponding authors: Tel, 82-42-860-4142; Fax, 82-42-860-4593; \\ E-mail, lesach @ kribb.re.kr (S.C. Lee) \\ Tel, 82-42-860-4268; Fax, 82-42-860-4593; \\ E-mail, khbae@ $@$ kribb.re.kr (K.H. Bae) \\ *These authors contributed equally to this work. \\ DOI 10.3858/emm.2008.40.6.677
}

Accepted 18 August 2008

Abbreviations: $\mathrm{AD}$, atopic dermatitis; 2-DE, two-dimensional electrophoresis

\begin{abstract}
Atopic dermatitis (AD) is an inflammatory skin disorder that is both uncomfortable and distressing to patients, and its prevalence has been steadily increasing. It is obvious that the identification of efficient markers of $A D$ in plasma would offer the possibility of effective diagnosis, prevention, and treatment strategies. In this study, a proteomic approach was used to analyze plasma glycoproteins from both children with $A D$ and healthy child donors. Several protein spots showing significant quantitative changes in the $A D$ patients were identified. Through sequential studies, it was confirmed that CD5L and ApoE were significantly up-regulated or down-regulated, respectively, in the plasma from $A D$ patients compared with that from healthy donors. In addition, we suggest that the up-regulated CD5L in AD patients causes eosinophilia by inhibiting apoptosis or promoting the proliferation of eosinophils either in combination with or without IL-5. The glycoproteomic data in this study provides clues to understanding the mechanism of atopic alterations in plasma and suggests AD-related proteins can be used as candidate markers for $A D$.
\end{abstract}

Keywords: apolipoproteins E; CD5L protein, human; dermatitis, atopic; glycoproteins; plasma; proteomics

\section{Introduction}

Atopic dermatitis (AD) is a common pruritic and chronically relapsing inflammatory skin disease. AD commonly occurs in infancy and early childhood, but can also start or persist in adulthood (Abramotiv, 2005; Scirica et al., 2007). The pathophysiology of $A D$ includes a disturbed skin barrier function, frequent allergic responses to allergens, defects in the antimicrobial immune defense, and a genetic predisposition. The number of $A D$ patients has increased with modernization and industrialization; particularly, a dramatic increase of the incidence of $A D$ has occurred in industrialized countries (Gold and Kemp, 2005). To develop effective therapeutic strategies and monitor the progress of an $A D$ patient, a deeper understanding of the complex pathogenesis of $A D$ is necessary.

Proteomic approaches have been applied to analyze many diseases and to probe for therapeutic purposes (Yuk and Ha, 2005; Lee et al., 2006; Kang et al., 2007; Lovestone et al., 2007). Among various subproteomes, the plasma proteome represents comprehensive physiological or pathological states. Thus, analyzing the plasma proteome can provide valuable information for mining disease marker proteins. Glycoproteome is also a major subproteome: many clinical biomarkers and therapeutic targets are glycoproteins. In particular, the glycosylation patterns are influenced considerably by the physiological status (Kim et al., 2004; Zhao et al., 2006). Therefore, in this study, a differential glycoprotein profiling of plasma trials of healthy donors and $A D$ patients was performed. Compared with the healthy donors, several differentially expressed proteins were identified in the results of $A D$ patients. Among them, it was found that CD5L and ApoE are potential biomarkers in the diagnosis of $A D$ or in tracking its progress.

\section{Materials and Methods}

\section{Reagents}

The anti-CD5L antibody (AF2797) and recom- 
binant CD5L protein (2797-CL, MN) were procured from R\&D Systems (Minneapolis, MN). The antiApoE antibody was supplied by Santa Cruz Biotechnology (Santa Cruz, CA). The urea, DTT, immobilized $\mathrm{pH}$ gradient (IPG) buffer, and the drystrip cover fluid were obtained from GE HealthCare (Uppsala, Sweden). The CHAPS, Tris, glycine, iodoacetamide, bromophenol blue, thiourea, and ammonium bicarbonate were provided by Sigma (St. Louis, MO).

\section{Subjects}

Human plasma samples were taken from healthy donors and patients with $A D$. The age of both the control and $A D$ patients ranged from 2 to 7 years old. The protocols of this study were approved by the Institutional Review Board (IRB) of KRIBB with the informed consent of the healthy donors and $A D$ patients. Diagnosis of $A D$ was based on the criteria proposed by Hanifin and Rajka (Hanifin and Rajka, 1980) for the criteria to assess the severity of AD, SCORAD (SCORing Atopic Dermatitis) was used (Table 1). The plasma parameters were measured in a clinical laboratory, and all clinical data are summarized in Table 1. The control group consisted of eight children of similar age without a personal or family history of atopic diseases.

\section{Purification of glycoproteins from plasma}

To selectively isolate the glycoproteins from the plasma, a Qproteome total glycoprotein kit (Qia37551, Qiagen, Valencia, CA) was used. First, the spin column was washed with $2.5 \mathrm{ml}$ binding buffer containing $20 \mu \mathrm{l}$ of protease inhibitor solution. Then, $50 \mu$ of the plasma sample diluted with 500 $\mu l$ of binding buffer was loaded onto the column and incubated. Next, the column was centrifuged for $2 \mathrm{~min}$ at $500 \mathrm{rpm}$ to remove the nonbonding fraction. After that, the column was washed with $750 \mu \mathrm{l}$ of binding buffer twice to wash off the nonspecific binding. The captured glycoproteins were eluted with $100 \mu \mathrm{l}$ of elution buffer ME twice and then with $100 \mu \mathrm{l}$ of elution buffer SE three times. The eluted fraction was collected via centrifugation at $500 \mathrm{rpm}$ for $2 \mathrm{~min}$. The eluted fractions were pooled and a DC protein assay kit (BioRad, Hercules) was used to monitor the protein concentrations.

\section{2-DE and image analysis}

The samples were applied to precast IPG strips with a nonlinear $\mathrm{pH}$ range of 4-7. Samples were applied via the rehydration of the IPG strips in a sample solution (8 M Urea, $2 \%$ Thiourea, $4 \%$ CHAPS, $1 \mathrm{mM}$ DTT, 0.5\% IPG buffer, a trace amount of bromophenol blue, and $50 \mathrm{mM}$ Tris- $\mathrm{HCl}$, $\mathrm{pH}$ 7.5) for more than $12 \mathrm{~h}$ and run for a first-dimensional IEF. After the IEF, the IPG strips were equilibrated twice for $15 \mathrm{~min}$. The first equilibrium solution contained $50 \mathrm{mM}$ of $\mathrm{pH} 8.8 \mathrm{Tris}-\mathrm{HCl}$ buffer with $6 \mathrm{M}$ urea, $20 \%$ glycerol, $2 \%$ SDS, and $1 \%$ DTT. In the second equilibrium solution, the DTT was replaced with $2.5 \%$ iodoacetamide. The proteins in the equilibrated strips were separated using a second-dimensional $12 \%$ SDS-PAGE. After electrophoresis, the protein spots were visualized using Coomassie staining. The images were then processed with Phoretix 2-DE expression software (Nonlinear Dynamics Ltd., UK). The spot volumes were normalized based on the total spot volume of each gel. The protein spot intensity was defined as the normalized spot volume that is the ratio of the single spot volume to the total spot volume on a 2-D gel (total spot normalization). Computer analysis allowed the automatic detection and quantification of the protein spots as well as matching between the control gels and gels from $A D$ samples. Statistical significance was accepted at a level of $P<0.05$.

\section{In-gel digestion and mass spectrometry}

The spots of interest were manually excised. The excised protein spots were digested using trypsin for $16-24 \mathrm{~h}$ at $37^{\circ} \mathrm{C}$. The digested peptides were extracted via sonication for 25 min with an extraction solution $[50 \%$ acetonitrile (ACN) and $2.5 \%$ trifluoroacetic acid (TFA)], and the extracted peptides were dried in a vacuum. Then, the extracted peptides were resuspended in $10 \mu \mathrm{l} 0.1 \%$ TFA followed by desalting/concentration with $\mu$ ZipTipC 18 (Millipore Co. Bedford, MA). For peptide mass fingerprinting, the desalted peptides were dissolved with $1 \mu \mathrm{l}$ of $50 \% \mathrm{ACN}$ and $0.1 \%$ TFA, and a $0.5 \mu \mathrm{l}$ drop of peptide was applied to the target plate and allowed to dry in air. The mass spectra were acquired via an Axima CFR+ matrix-assisted laser desorption/ionization time-of-flight mass spectrometry (MALDI-TOF-MS, Shimadzu Biotech, Japan). The obtained mass spectra were analyzed using a MASCOT PMF search. The following parameters were used: the database was NCBInr (species: Homo sapiens) with the maximum number of missed cleavage by trypsin at 1 . The mass tolerance ranged from \pm 50 to $\pm 100 \mathrm{ppm}$. The allowed peptide modification was carbamidomethylation in a fixed modification mode. The proteins that failed by peptide mass fingerprinting were tried 
again using LC-MS/MS (Q-TOF Premier, Micromass, UK).

\section{Western blot analysis}

The samples were separated using SDS-PAGE. The protein was transferred onto a PVDF membrane and blotted with the primary antibody using standard methods. Detection was achieved using ECL plus Western blotting reagents (Pierce). The bands were scanned with a flat-bed scanner and analyzed using image analysis software.

\section{Cell viability assay of AML14.3D10 cells}

AML 14.3D10 cells were maintained in a RPMI 1640 medium containing 10\% v/v FBS (Gibco, Carlsbad, CA) and 1\% v/v Antibiotic-Antimycotic (Gibco, Carlsbad, CA). Approximately $1 \times 10^{6}$ AML14.3D10 cells were resuspended in $20 \mathrm{ml}$ of fresh complete medium and incubated for $24 \mathrm{~h}$. Then, the cells were treated with IL-5 (final 50 $\mathrm{ng} / \mathrm{ml}$ ) or dexamethasone (final $10 \mu \mathrm{M}$ ) in combination with various concentrations of CD5L for $24 \mathrm{~h}$ at $37^{\circ} \mathrm{C}$ in a $5 \% \mathrm{CO}_{2}$ incubator. Before harvesting, the cultured cells were washed twice with ice-cold PBS. The cell viability was assessed by measuring the ability of the cells to MTT, as previously described in the literature (Kang et al., 2007; Lee et al., 2007).

\section{Results and Discussion}

\section{Clinical data in plasma samples of $A D$ patients}

$A D$ is very common in children, typically before the age of 5 (Scirica et al., 2007). Therefore, the focus of this investigation is on $A D$ in young children. The diagnosis and severity of $A D$ were monitored according to the SCORAD value of the patients. SCORAD was proposed to standardize the clinical evaluation of $A D$ patients; it is now widely used as a clinical tool for assessing the severity of AD. The SCORAD index values of the AD patients in this study were between 21 and 80 . The majority of patients (6 of 8 patients) had a SCORAD index above 31. Therefore, the clinical picture was moderately severe. All clinical data, including the SCORAD values, are summarized in Table 1.

\section{Isolation of glycoproteins from plasma of healthy donors and $A D$ patients}

Protein glycosylation plays a vital role in a wide

Table 1. Clinical data of patients with atopic dermatitis.

\begin{tabular}{lcccccccc}
\hline Patient No. & $\begin{array}{c}\text { Age } \\
\text { (year) }\end{array}$ & Gender & $\begin{array}{c}\text { Duration of } \\
\text { symptoms (year) }\end{array}$ & $\begin{array}{c}\text { Eosinophils } \\
(\%)\end{array}$ & $\begin{array}{c}\text { SCORAD } \\
\text { score }\end{array}$ & $\begin{array}{c}\text { Total } \\
\operatorname{lgE}(\text { IU) }\end{array}$ & $\begin{array}{c}\text { Specific } \\
\operatorname{lgE}^{\mathrm{a}}\end{array}$ & $\begin{array}{c}\text { Skin Prick } \\
\text { test }\end{array}$ \\
\hline 9745656 & 5 & $\mathrm{~F}$ & 2 & 4.5 & 40 & 149 & - & DP, DF \\
9809813 & 2 & $\mathrm{M}$ & 1 & 8.1 & 36 & 188 & Cat, Dog & ND \\
9849676 & 2 & $\mathrm{M}$ & 1 & 3.8 & 50 & 300 & DP, DF & ND \\
9861479 & 5 & $\mathrm{~F}$ & 4 & 0.7 & 27 & 300 & - & Egg, Cat, Aspergillus \\
9869052 & 3 & $\mathrm{M}$ & 1 & 3.4 & 52 & 300 & Dog & ND \\
9871941 & 7 & $\mathrm{M}$ & 3 & 3.4 & 54 & 188 & DF & ND \\
9875962 & 4 & $\mathrm{~F}$ & 1 & 2.3 & 21 & 37 & Milk & - \\
9808588 & 5 & M & 5 & 6.1 & 80 & 206 & - & - \\
\hline
\end{tabular}

${ }^{\mathrm{a} D F}$, Dermatophagoides farinae; DP, Dermatophagoides pteronyssinus; ND, not determined.

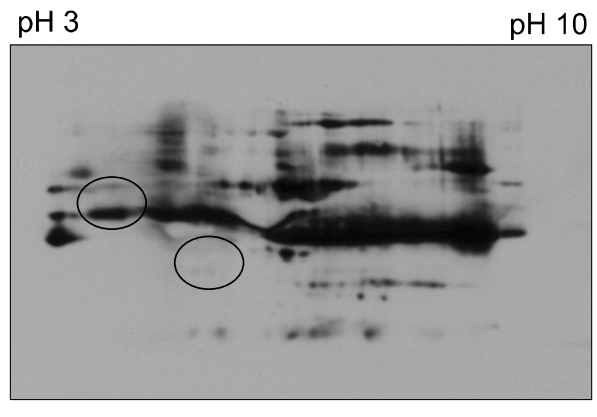

Healthy donor

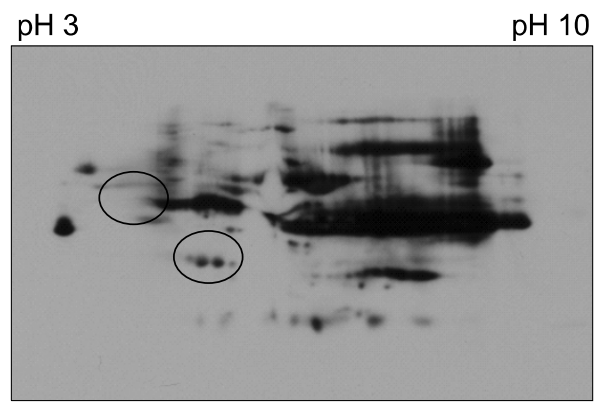

$A D$ patient
Figure 1. Representative LCA lectin blot analysis of plasma from healthy control and $\mathrm{AD}$ patient. Total plasma proteins extracted from the healthy donors and the $A D$ patients were separated on 2-DE gels and transferred onto a PVDF membrane. The membrane was subjected to a lectin blot and treated with biotin-labeled LCA. Spots that displayed differently (marked by circles) were detected. 


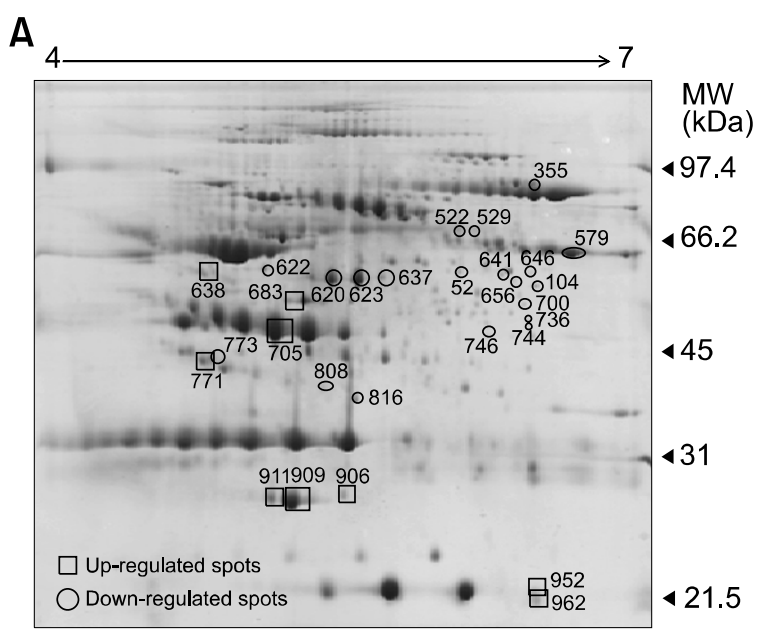

B

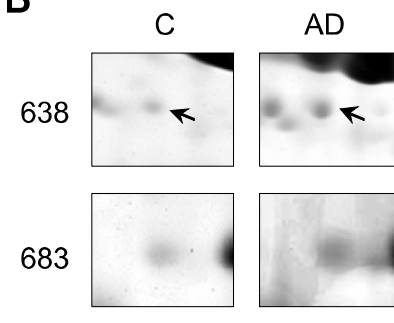

705

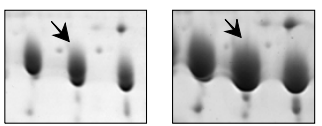

52
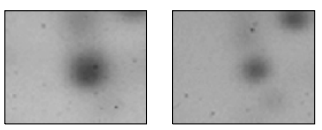

355
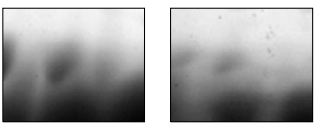

522
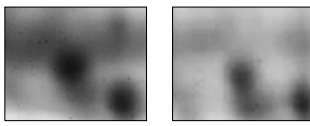

529
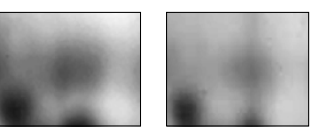

579
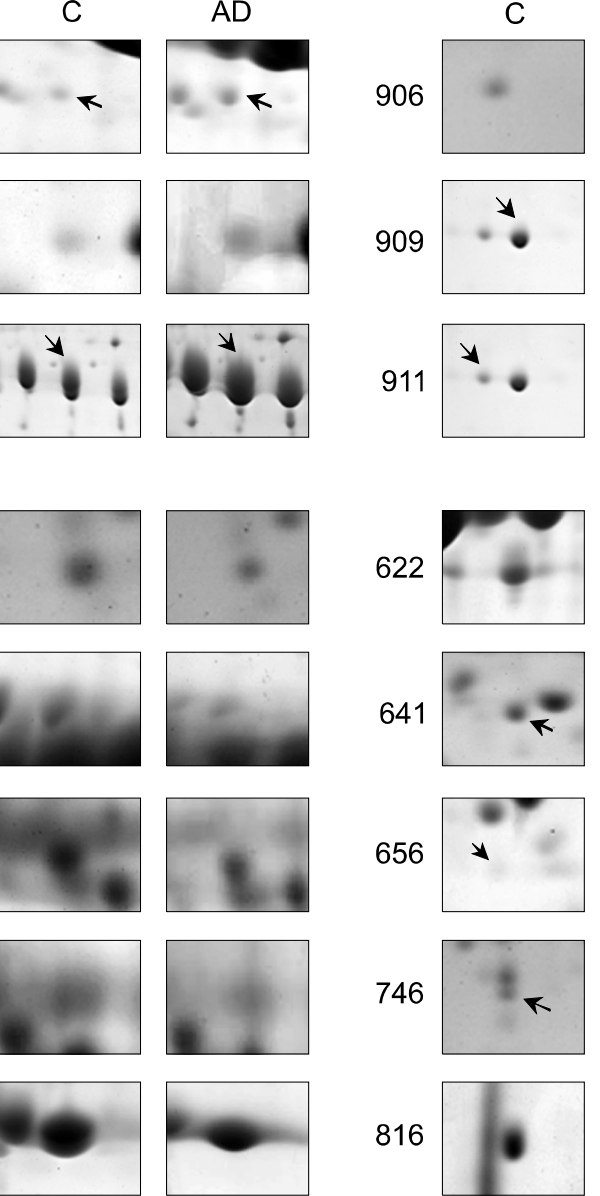

C

$A D$
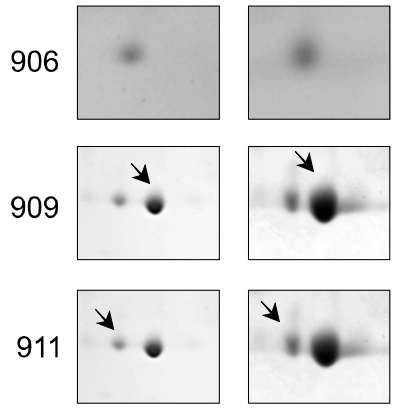

622
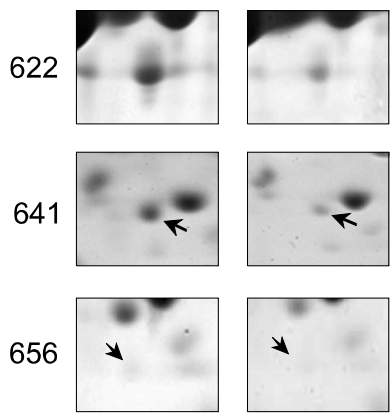

746
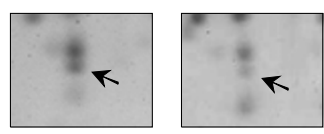

816

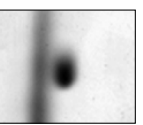

C
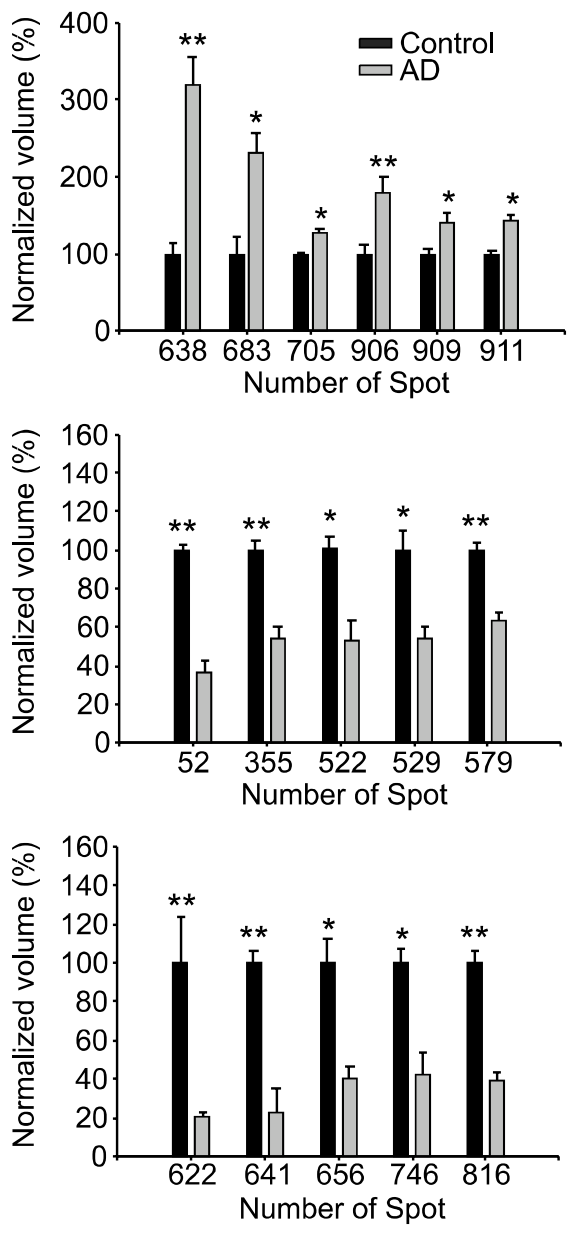

${ }^{*} P<0.05 ;{ }^{* *} P<0.01$

Figure 2. The analysis of $A D$ plasma using 2-DE. (A) Representative 2-DE map of plasma from an $A D$ patient. The differentially expressed protein spots are indicated by a circle or rectangle. The results are summary of 2-DE results from all AD patients and normal control. The spots indicated were identified using either MALDI-TOF or LC-MS/MS, as outlined in Table 2. (B) Enlargement of the 2-DE gel on up-regulated and down-regulated spots. (C) Quantitation of the proteins shown in (B). The control volume is expressed as $100 \%$ and the volumes of the AD patients as values relative to the control. The data represent the mean values $\pm \mathrm{SD} .{ }^{*} P<0.05 ;{ }^{* *} P<0.01$. 
range of cellular processes, such as cell adhesion and signaling, stabilization of protein folding and function, oncogenesis, and immune responses (Hakomori, 1989; Kim and Varki, 1997). It is proposed that nearly $50 \%$ of human plasma proteins are glycosylated. To test the possibility that the expression or glycosylation pattern of plasma glycoproteins are altered or changed in $A D$ patients, Lens culinaris agglutinin (LCA) lectin blot analyses of the plasma proteins obtained from healthy donors and $A D$ patients were initially conducted. LCA binds $\alpha 1,6$-fucose branching with a weak affinity, thus showing a relatively broad spectrum of carbohydrate moieties for recognition. Figure 1 shows the representative results of a 2-DE LCA lectin blot. It is noteworthy that the plasma from the $A D$ patients shows a somewhat different pattern compared with that from healthy donors. This result strongly suggests that differential expressions or glycosylation patterns of several glycoproteins may be related to AD pathogenesis. Next, to thoroughly investigate the differential expression profiling of glycoproteins from the plasma of $A D$ patients, analysis of the plasma glycoproteins was undertaken using proteomic tools. First, an LCA-sepharose 4B column was used to isolate the glycoproteins from the human plasma samples. However, this column did not efficiently remove most of the serum albumin; consequently, the presence of various low-abundant proteins on the 2-DE gel was masked (data not shown). It was then decided that a Qproteome total glycoprotein kit would be used to efficiently enrich the plasma glycoproteins. The total glycoprotein spin columns in the Qproteome total glycoprotein kit contained ConA and WGA lectins. They were used for the general enrichment of the total glycoprotein population from the plasma/serum samples. 1-DE gel analysis of the glycoprotein fractions shows efficient removal of albumin and a similar overall glycoprotein pattern of the plasma from the healthy donors and $A D$ patients (data not shown).

\section{Differentially expressed glycoprotein spots in plasma of patients with $A D$}

To investigate the glycoproteins that showed significant quantitative changes in the plasma between the healthy donors and the $A D$ patients, the plasma glycoproteins enriched by a Qproteome total glycoprotein kit were separated by 2-DE (Figure 2A). The protein spots that showed significant changes, greater than 1.5 fold in magnitude, between the healthy donors and the AD patients were scored. Statistical significance was accepted at a level of $P$ $<0.05$. A total of 29 spots showed a significant change in the AD patients. Among these, a total of 16 spots were identified using MALDI-TOF or ESI-Q TOF MS/MS. These are listed in Table 2. Of these, six spots including CD5L were up-regulated and ten spots including ApoE were down-regulated (Figures $2 \mathrm{~B}$ and $\mathrm{C}$, respectively). The glycoproteome results demonstrated that various proteins

Table 2. Sixteen differentially expressed glycoproteins in AD patients.

\begin{tabular}{|c|c|c|c|c|c|c|c|c|c|}
\hline $\begin{array}{l}\text { Spot } \\
\text { No. }\end{array}$ & ID & $\begin{array}{l}\text { Seq. } \\
\text { cov. }(\%)\end{array}$ & $\begin{array}{l}\text { Matched } \\
\text { peptides }\end{array}$ & $\mathrm{pl}$ & $\begin{array}{l}\text { Mass } \\
(\mathrm{kDa})\end{array}$ & $\begin{array}{l}\text { Expectation } \\
\text { value }\end{array}$ & $\begin{array}{l}\text { Mascot }^{a} \\
\text { (score) }\end{array}$ & $\mathrm{NCBI}$ & $\begin{array}{c}\text { Fold } \\
\text { change }\end{array}$ \\
\hline 52 & Fibrin $\beta$ & 33 & 13 & 7.95 & 51.3 & 9.9E-05 & 92 & gi|223002 & -2.77 \\
\hline 355 & Transferrin [Homo sapiens] & 11 & 10 & 6.81 & 77.0 & MS/MS & 385 & gi|15021381 & -1.88 \\
\hline 522 & IGHA1 protein [Homo sapiens] & 23 & 10 & 6.78 & 54.1 & 0.0023 & 78 & gi|62204992 & -1.83 \\
\hline 529 & IGHA1 protein [Homo sapiens] & 26 & 10 & 8.07 & 54.3 & 0.00099 & 82 & gi|16741036 & -1.66 \\
\hline 579 & $\beta$-fibrinogen precursor & 26 & 15 & 8.31 & 54.8 & MS/MS & 757 & gi|182430 & -1.65 \\
\hline 622 & Fibrinogen $\gamma$ chain & 32 & 10 & 5.37 & 51.4 & MS/MS & 594 & gi|14488402 & -3.28 \\
\hline 638 & $\begin{array}{l}\text { Serpin peptidase inhibitor, } \\
\text { clade A, member } 1\end{array}$ & 29 & 12 & 5.37 & 46.8 & 7.3E-06 & 103 & gi|6855601 & +2.64 \\
\hline 641 & Fibrin $\beta$ & 5 & 2 & 7.95 & 51.3 & $1.5 \mathrm{E}-10$ & 150 & gi|223002 & -3.23 \\
\hline 656 & Hemopexin precursor & 41 & 11 & 6.57 & 51.5 & MS/MS & 83 & gi|386789 & -2.41 \\
\hline 683 & CD5L [Homo sapiens] & 18 & 8 & 6.26 & 39.6 & 0.0051 & 75 & gi|37182111 & +2.19 \\
\hline 705 & HP protein [Homo sapiens] & 34 & 15 & 5.45 & 38.8 & 3.7E-06 & 106 & gi|78174390 & +1.51 \\
\hline 746 & Complement component 4B & 20 & 20 & 5.78 & 47.9 & 0.0062 & 78 & gi|40737343 & -2.21 \\
\hline 816 & Apolipoprotein E & 38 & 12 & 5.65 & 36.1 & MS/MS & 580 & gi|178849 & -2.33 \\
\hline 906 & Proapolipoprotein & 32 & 7 & 5.45 & 28.9 & MS/MS & 420 & gi|178775 & +1.82 \\
\hline 909 & Proapolipoprotein & 46 & 17 & 5.45 & 28.9 & MS/MS & 863 & gi|178775 & +1.50 \\
\hline 911 & $\begin{array}{l}\text { Chain C, Crystal structure of Lipid- } \\
\text { Free Human Apolipoprotein A-I }\end{array}$ & 71 & 23 & 5.27 & 28.0 & 4.6E-07 & 235 & gi|90108666 & +1.52 \\
\hline
\end{tabular}

${ }^{a}$ Mascot score greater than 61 are significant $(P<0.05)$. 
involved in blood clotting (coagulation), including fibrin $\beta$, fibrinogen $\gamma$, C4B4, and IGHA1 protein, were decreased in the plasma of the AD patients.

\section{Validation of ApoE protein level in AD patients}

To verify the differential expression of the ApoE protein, the plasma expression level of ApoE was also analyzed via Western blotting. As shown in Figure 3, the level of ApoE in the plasma from the AD patients was significantly reduced $(P<0.05)$. ApoE has long been known to be an essential constituent of plasma lipoproteins. In addition to its well-recognized roles in lipid metabolism and atherosclerogenesis, ApoE has been shown to be involved in several pathophysiologic processes not directly related to lipid transport. Recently, it was known that inflammation could impair lipoprotein metabolism and produce a wide variety of changes in the plasma concentrations of lipids and lipoproteins (Ripolles et al., 2006). In the glycoproteome data in this study, several apolipoproteins were differentially expressed. While ApoE was downregulated, proapolipoprotein and the crystal structure of lipid-free human apolipoprotein Al were upregulated. Therefore, it is speculated that the plasma lipoprotein level of the $A D$ patients changes as a result of the inflammatory reaction during $A D$ pathogenesis. Further studies regarding $A p o E$ are necessary to provide insight into the pathogenesis of $A D$ and whether $A p o E$ can be utilized as a potential specific marker protein for AD.

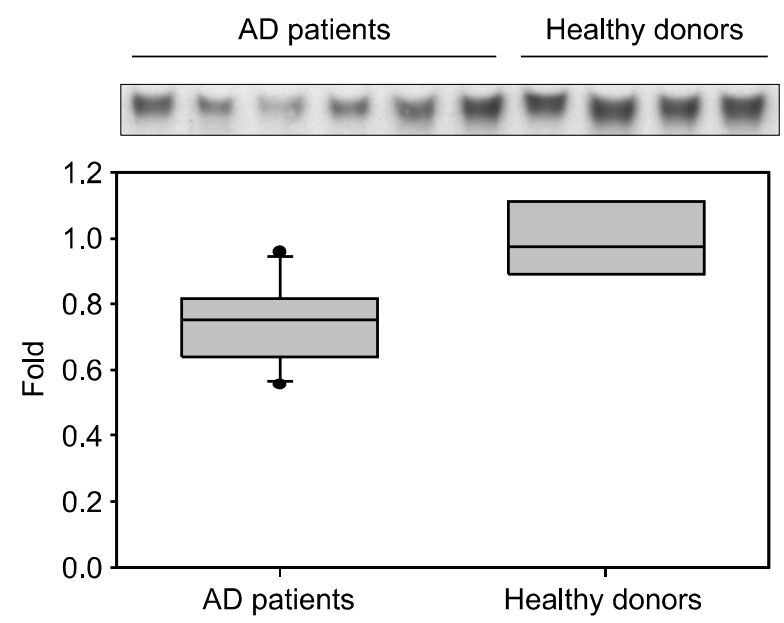

Figure 3. Validation of the ApoE expression level via Western blotting. (A) Western blot analyses of serum protein $(5 \mu \mathrm{l})$ from four healthy donors and six AD patients were conducted. (B) Quantitation analysis of the gel bands was conducted using Image J software. Significant differences $(P<0.05)$ were measured via a median plus ANOVA.

\section{Validation of $C D 5 L$ protein expression level in $A D$ patients and the effect on the proliferation of eosinophils}

CD5L (also known as an IgM-associated peptide, apoptosis inhibitor 6 , and $\mathrm{Sp} \alpha$ ) is a soluble protein belonging to group $\mathrm{B}$ of the scavenger receptor cysteine-rich (SPCR) superfamily (Sarrias et al., 2004, 2005). It is expressed through macrophages present in lymphoid tissues, and it binds to different cells of the immune system, which suggests that it may play a role in immune system regulation. In addition, CD5L appears to play a role as an inhibitor of apoptosis. It was demonstrated that CD5L supports macrophage survival and enhances the phagocytic function of macrophages in Corynebacterium parvum-induced hepatitis (Haruta et al., 2001). Recently, it was reported that CD5L inhibits the apoptosis of T cells and NKT cells in Corynebacterium-induced granuloma formation in mice (Kuwata et al., 2003). Yusa et al. also reported that $\mathrm{CD} 5 \mathrm{~L}$ induced strong and sustained growth inhibition of B lymphocytes in combination with TGF- $\beta 1$ (Yusa et al., 1999). Therefore, it has been proposed that CD5L has different functions depending on the types of target cells and combination with other cytokines.

A Western blot analysis was conducted on the plasma from the $A D$ patients using anti-CD5L antibody (Figure 4A). As shown, CD5L is significantly up-regulated in the plasma of the $A D$ patients. Following this, we tested the effect of CD5L on the proliferation of the AML14.3D10 human eosinophil cell line (Figure 4B). The AML14.3D10 human myeloid leukemic cell line has been used as a model cell line for the study of eosinophil (Baumann and Paul, 1998; Yoon et al., 2005). Interestingly, CD5L increases the proliferation of the AML14.3D10 cell in a dose-dependent manner with IL-5 (Figure 4C). Furthermore, CD5L prevents AML14.3D10 cells from apoptosis or the growth inhibition effects induced by treatment with dexamethasone (Figure 4D). These data regarding the effect of CD5L on the proliferation of the eosinophil cell line strongly suggest that there is an interconnection between the CD5L plasma level and $A D$. Eosinophils act as effectors in the inflammatory reactions of allergic diseases including $A D$ (Trautmann et al., 2001; Simon et al., 2004; Ryu et al., 2007). AD patients suffer from eosinophilia, an accumulation of eosinophils due to the increased survival or decreased apoptosis of eosinophils, which correlate with disease activity (Trautmann et al., 2000; Domae et al., 2003). It is known that the inhibition of the apoptosis of eosinophils can be achieved by an increased expression of survival factors, as well as a disruption of death signals 
A

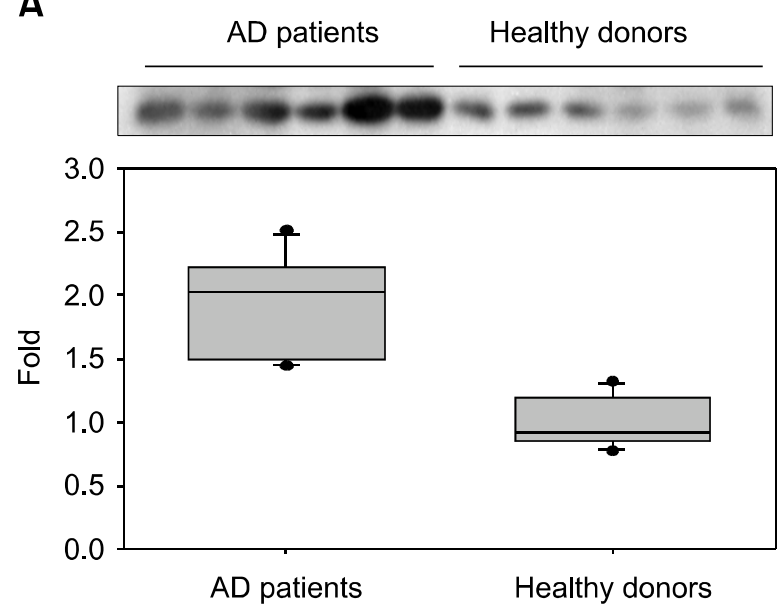

C

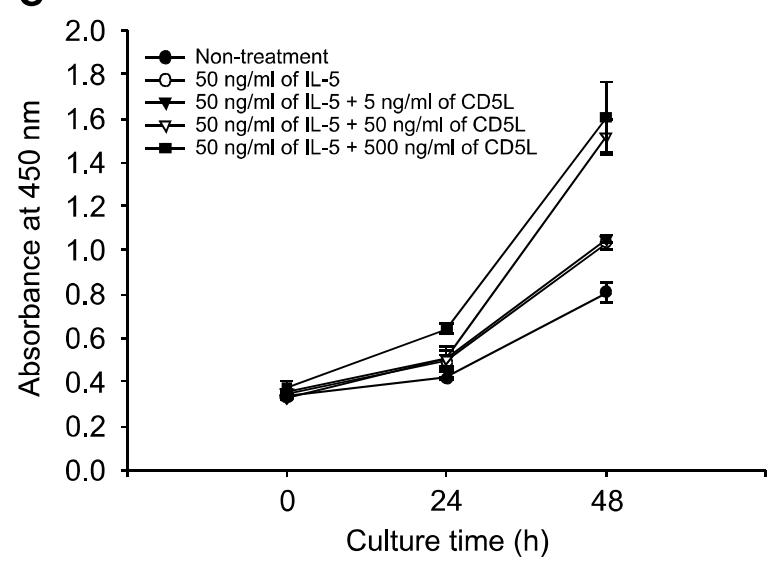

B

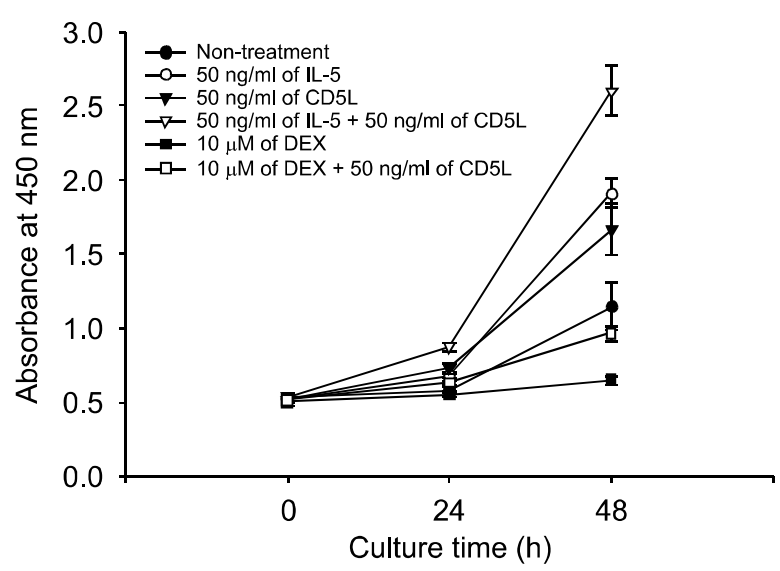

D

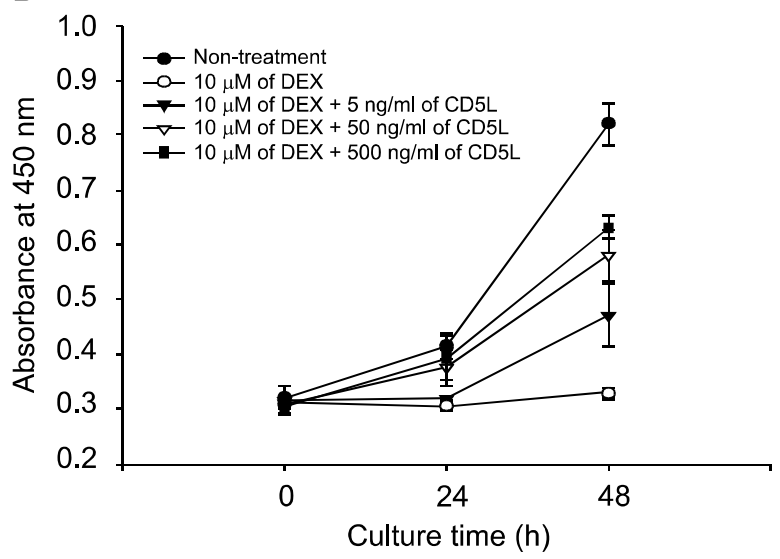

Figure 4. Validation of the CD5L expression level and effect of CD5L on AML14.3D10 proliferation. (A) Western blot analysis of the serum protein (5 $\mu$ l) from six healthy donors and six AD patients were conducted. Quantitation analyses of the gel bands were conducted using Image $\mathrm{J}$ software. Significant differences $(P<0.01)$ were measured via a median plus ANOVA. (B) CD5L increases the proliferation of the AML14.3D10 cells. AML14.3D10 cells were seeded into 96 well plates and grown for $24 \mathrm{~h}$. The cells were then treated with CD5L ( \pm IL-5 or Dexamethasone). At each time point, the cell viability was measured. (C) CD5L induces the proliferation of AML14.3D10 cells in a dose-dependent manner in the presence of IL-5. (D) CD5L induces the proliferation of AML14.3D10 cells in a dose-dependent manner in the presence of Dexamethasone.

(Simon, 2000). It is known that IL-5 is the most critical cytokine in mediating increased eosinophil differentiation, activation, and survival (Oldhoff et al., 2005; Simon and Simon, 2007). Based on these results and other reports, it is suggested that an increased CD5L may induce eosinophilia in AD patients in either in combination with or without IL-5 as a survival factor. Therefore, CD5L may be feasible as a potential biomarker in the diagnosis and treatment of $A D$, although CD5L was reported as candidate marker in asthma and liver cirrhosis (Wu et al., 2005; Gangadharan et al., 2007).

In conclusion, several glycoproteins that may be involved in AD were identified through a glycoproteomic approach, even though the number of patients was rather small. Among them, it was confirmed that CD5L and ApoE were differentially expressed in the plasma of $A D$ patients. According to gene expression data from normal and $A D$ skin tissue samples (http://www.ncbi.nlm.gov/geo/gds browse.cgi?gds=2381), CD5L and ApoE are also differentially expressed in $A D$ patients, which is consistent with our proteomic results. In future studies, we plan to investigate the detailed roles of the altered levels of these proteins during the progression of $A D$ pathogenesis and whether or not these changes are specific to AD. This glycoproteomic analysis and further characterization of the identified proteins can provide valuable information that can build a deeper unders- 
tanding of $A D$.

\section{Acknowledgements}

We thank Drs. Haryoung Poo and Jin Woong Chung for carefully reading this manuscript. This work was supported by a grant from KRIBB (to K.-H. Bae), Korea Research Council of Fundamental Science and Technology (to K.-H. Bae), and a Molecular and Cellular BioDiscovery Research Program (to S.C. Lee) of the Korean government (MOST), Korea.

\section{References}

Abramotiv W. Atopic dermatitis. J Am Acad Dermatol 2005;53:86-93

Baumann MA, Paul CC. The AML14 and AML14.3D10 cell lines: a long-overdue model for the study of eosinophils and more. Stem Cells 1998;16:16-24

Domae M, Sagara H, Sakaue M, Fukuda T, Kamikawa Y. The antiallergic drug oxatomide promotes human eosinophil apoptosis and suppresses IL-5-induced eosinophil survival. J Allerg Clin Immunol 2003;111:567-72

Gangadharan B, Antrobus R, Dwek RA, Zitzmann N. Novel serum biomarker candidates for liver fibrosis in hepatitis $C$ patients. Clin Chem 2007;53:1792-9

Gold MS, Kemp AS. Atopic disease in childhood. Med J Aust 2005;182:298-304

Hakomori S. Aberrant glycosylation in tumors and tumorassociated carbohydrate antigens. Adv Cancer Res 1989; 52:257-331

Hanaffin JM, Rajka G. Diagnostic feature of atopic dermatitis. Acta Derm Venereol Suppl (Stockh) 1980;92:44-7

Haruta I, Kato Y, Hashimoto E, Minjares C, Kennedy S, Uto H, Yamauchi K, Kobayashi M, Yusa S, Muller U, Hayashi N, Miyazaki T. Association of AIM, a novel apoptosis inhibitory factor, with hepatitis via supporting macrophage survival and enhancing phagocytotic function of macrophages. J Biol Chem 2001;276:22910-4

Kang TH, Bae K-H, Yu M-j, Kim WK, Hwang H-R, Jung H, Lee PY, Kang S, Yoon T-S, Park SG, Ryu SE, Lee SC. Phosphoproteomic analysis of neuronal cell death by glutamateinduced oxidative stress. Proteomics 2007;7:2624-35

Kang S, Kim EY, Bahn YJ, Chung JW, Lee DH, Park SG, Yoon T-S, Park BC, Bae K-H. A proteomic analysis of the effect of MAPK pathway activation on L-glutamate-induced neuronal cell death. Cell Mol Biol Lett 2007;12:139-47

Kim YJ, Varki A. Perspectives on the significance of altered glycosylation of glycoproteins in cancer. Glycoconj J 1997; 14:569-76

Kim Y-S, Hwang SY, Oh S, Sohn H, Kang HY, Lee JH, Cho EW, Kim JY, Yoo JS, Kim CH, Miyoshi E, Taniguchi N, Ko JH. Identification of target proteins of $\mathrm{N}$-acetylglucosaminyltransferase $\mathrm{V}$ and fucosyltransferase 8 in human gastric tissues by glycomic approach. Proteomics 2004;4:3353-8
Kuwata K, Watanabe H, Jiang SY, Yamamoto T, TomiyamaMiyaji C, Abo T, Miyazaki T, Naito M. AIM inhibits apoptosis of $T$ cells and NKT cells in Corynebacterium-induced granuloma formation in mice. Am J Pathol 2003;162:837-47

Lee EJ, Kim SH, Kwak YE, Kim J. Heterogeneous nuclear ribonuclear protein $\mathrm{C}$ is increased in the celecoxib-induced growth inhibition of human oral squamous cell carcinoma. Exp Mol Med 2006;38:203-9

Lee Y, Park H-W, Park SG, Cho S, Park BC, Lee DH. Proteomic analysis of glutamate-induced toxicity in HT22 cells. Proteomics 2007;7:185-93

Lovestone S, Guntert A, Hye A, Lynham S, Thambisetty M, Ward M. Proteomics of Alzheimer's disease: understanding mechanisms and seeking biomarkers. Expert Rev Proteomics 2007;4:227-38

Oldhoff JM, Darsow U, Werfel T, Katzer K, Wulf A, Laifaoui J, Hijnen DJ, Plotz S, Knol EF, Kapp A, Bruijnzeel-Koomen CA, Ring J, de Bruin-Weller MS. Anti-IL-5 recombinant humanized monoclonal antibody (mepolizumab) for the treatment of atopic dermatitis. Allergy 2005;60:693-6

Ripolles Piquer B, Nazih H, Bourreille A, Segain JP, Huvelin JM, Galmiche JP, Bard JM. Altered lipid, apolipoprotein, and lipoprotein profiles in inflammatory bowel disease: consequences on the cholesterol efflux capacity of serum using Fu5AH cell system. Metabolism 2006;55:980-8

Ryu SI, Kim WK, Cho HJ, Lee PY, Jung H, Yoon TS, Moon $\mathrm{JH}$, Kang S, Poo H, Bae KH, Lee SC. Phosphoproteomic analysis of AML14.3D10 cell line as a model system of eosinophilia. J Biochem Mol Biol 2007;40:765-72

Sarrias MR, Padilla O, Monreal Y, Carrascal M, Abian J, Vivers J, Yelamos J, Lozano F. Biochemical characterization of recombinant and circulating human Sp $\alpha$. Tissue Antigens 2004;63:335-44

Sarrias MR, Rosello S, Sanchez-Barbero F, Sierra JM, Vila $\mathrm{J}$, Yelamos J, Casals C, Lozano F. A role for human Spa as a pattern recognition receptor. J Biol Chem 2005;280: 35391-98

Scirica CV, Gold DR, Ryan L, Abulkerim H, Celedon JC, Platts-Mills TA, Naccara LM, Weiss ST, Litonjua AA. Predictors of cord blood lgE levels in children at risk for asthma and atopy. J Allergy Clin Immunol 2007;119:81-8

Simon D, Braathen LR, Simon H-U. Eosinophils and atopic dermatitis. Allergy 2004;59:561-70

Simon D, Simon H-U. Eosinophilic disorders. J Allergy Clin Immunol 2007;119:1291-300

Simon HU. Regulation of apoptosis in diseases associated with eosinophilia. Resp Med 2000;94:1258-9

Trautmann A, Akdis M, Blaser K, Akdis CA. Role of dysregulated apoptosis in atopic dermatitis. Apoptosis 2000;5:425-9

Trautmann A, Akdis M, Klunker S, Blaser K, Akdis CA. Role of apoptosis in atopic dermatitis. Int Arch Aller Immunol 2001;124:230-2

Wu J, Kobayashi M, Sousa EA, Liu W, Cai J, Goldman SJ, Dorner AJ, Projan SJ, Kavuru MS, Qiu Y, Thomassen MJ. Mol 


\section{Cell Proteomics 2005;4:1251-64}

Yoon SW, Kim TY, Sung MH, Kim CJ, Poo H. Comparative proteomic analysis of peripheral blood eosinophils from healthy donors and atopic dermatitis patients with eosinophilia. Proteomics 2005;5:1987-95

Yuk JS, Ha KS. Proteomic applications of surface plasmon resonance biosensors: analysis of protein arrays. Exp Mol Med 2005;37:1-10
Yusa S, Ohnishi S, Onodera T, Miyazaki T. AIM, a murine apoptosis inhibitory factor, induces strong and sustained growth inhibition of $B$ lymphocytes in combination with TGF- $\beta 1$. Eur J Immunol 1998;29:1086-93

Zhao J, Simeone DM, Heidt D, Anderson MA, Lubman DM. Comparative serum glycoproteomics using lectin selected sialic acid glycoproteins with mass spectrometric analysis: application to pancreatic cancer serum. J Proteome Res 2006;5:1792-802 